\title{
Aggregate PR Interval
}

National Cancer Institute

\section{Source}

National Cancer Institute. Aggregate PR Interval. NCI Thesaurus. Code C117773.

An aggregate PR value based on the measurement of PR intervals from multiple beats

within a single ECG. The method of aggregation, which can vary, is typically a measure of central tendency such as the mean. (CDISC) 